University of Nebraska - Lincoln

DigitalCommons@University of Nebraska - Lincoln

\title{
Investigations of transcript expression in fathead minnow (Pimephales promelas) brain tissue reveal toxicological impacts of RDX exposure
}

\author{
Kurt A. Gust \\ US Army Corps of Engineers, kurt.a.gust@erdc.usace.army.mil \\ Mitchell S. Wilbanks \\ US Army Corps of Engineers \\ Xin Guan \\ SpecPro Inc. \\ Mehdi Pirooznia \\ Johns Hopkins University \\ Tanwir Habib \\ SpecPro Inc.
}

See next page for additional authors

Follow this and additional works at: https://digitalcommons.unl.edu/usarmyresearch

Part of the Operations Research, Systems Engineering and Industrial Engineering Commons

Gust, Kurt A.; Wilbanks, Mitchell S.; Guan, Xin; Pirooznia, Mehdi; Habib, Tanwir; Yoo, Leslie; Wintz, Henri; Vulpe, Chris D.; and Perkins, Edward J., "Investigations of transcript expression in fathead minnow (Pimephales promelas) brain tissue reveal toxicological impacts of RDX exposure" (2011). US Army Research. 128.

https://digitalcommons.unl.edu/usarmyresearch/128

This Article is brought to you for free and open access by the U.S. Department of Defense at DigitalCommons@University of Nebraska - Lincoln. It has been accepted for inclusion in US Army Research by an authorized administrator of DigitalCommons@University of Nebraska - Lincoln. 


\section{Authors}

Kurt A. Gust, Mitchell S. Wilbanks, Xin Guan, Mehdi Pirooznia, Tanwir Habib, Leslie Yoo, Henri Wintz, Chris D. Vulpe, and Edward J. Perkins 


\title{
Investigations of transcript expression in fathead minnow (Pimephales promelas) brain tissue reveal toxicological impacts of RDX exposure
}

\author{
Kurt A. Gust ${ }^{\mathrm{a}, *}$, Mitchell S. Wilbanks a ${ }^{\mathrm{a}}$ Xin Guan ${ }^{\mathrm{b}}$, Mehdi Pirooznia ${ }^{\mathrm{c}}$, Tanwir Habib ${ }^{\mathrm{b}}$, Leslie Yoo $^{\mathrm{d}}$, \\ Henri Wintz ${ }^{\mathrm{e}}$, Chris D. Vulpe ${ }^{\mathrm{d}}$, Edward J. Perkins ${ }^{\mathrm{a}}$ \\ a US Army Corps of Engineers, Environmental Laboratory EP-P, Vicksburg, MS 39180, United States \\ b SpecPro Inc., 3909 Halls Ferry Rd., ERDC-USACE-EL-EP-P, Vicksburg, MS 39180, United States \\ c The Johns Hopkins University, School of Medicine, Baltimore, MD 21287, United States \\ d Perennial Environmental Services, LLC, Houston, TX 77092, United States \\ e Department of Nutritional Sciences and Toxicology, University of California, Berkeley, CA 94720, United States
}

\section{A R T I C L E I N F O}

\section{Article history:}

Received 19 April 2010

Received in revised form

15 September 2010

Accepted 21 September 2010

\section{Keywords:}

Genomics

Microarray analysis

Pimephales promelas

Fathead minnow

Explosives

\begin{abstract}
A B S T R A C T
Production, usage and disposal of the munitions constituent (MC) cyclotrimethylenetrinitramine (RDX) has led to environmental releases on military facilities. The chemical attributes of RDX are conducive for leaching to surface water which may put aquatic organisms at risk of exposure. Because RDX has been observed to cause aberrant neuromuscular effects across a wide range of animal phyla, we assessed the effects of RDX on central nervous system (CNS) functions in the representative aquatic ecotoxicological model species, fathead minnow (Pimephales promelas). We developed a fathead minnow brain-tissue cDNA library enriched for transcripts differentially expressed in response to RDX and trinitrotoluene (TNT) exposure. All 4,128 cDNAs were sequenced, quality filtered and assembled yielding 2230 unique sequences and 945 significant blastx matches $\left(E \leq 10^{-5}\right)$. The cDNA library was leveraged to create custom-spotted microarrays for use in transcript expression assays. The impact of RDX on transcript expression in brain tissue was examined in fathead minnows exposed to RDX at $0.625,2.5,5,10 \mathrm{mg} / \mathrm{L}$ or an acetone-spike control for 10 days. Overt toxicity of RDX in fathead minnow occurred only at the highest exposure concentration resulting in 50\% mortality and weight loss. Conversely, Bayesian analysis of microarray data indicated significant changes in transcript expression at concentrations as low as $0.625 \mathrm{mg} / \mathrm{L}$. In total, $154 \mathrm{cDNAs}$ representing 44 unique transcripts were differentially expressed in RDX exposures, the majority of which were validated by reverse transcriptase-quantitative PCR (RT-qPCR). Investigation of molecular pathways, gene ontology (GO) and individual gene functions affected by RDX exposures indicated changes in metabolic processes involved in: oxygen transport, neurological function, calcium binding/signaling, energy metabolism, cell growth/division, oxidative stress and ubiquitination. In total, our study indicated that RDX exposure affected molecular processes critical to CNS function in fathead minnow.
\end{abstract}

Published by Elsevier B.V.

\section{Introduction}

Cyclotrimethylenetrinitramine (RDX) is a common munitions constituent that has been produced and deployed in relatively large volumes by the US military. Both production and use in training exercises has lead to environmental contamination on military installations (Talmage et al., 1999; Pennington et al., 2006). Although most of this contamination has been observed in soils, the physical properties of RDX are conducive to leaching into ground and surface waters thereby placing aquatic organisms at risk of exposure (Talmage et al., 1999).

\footnotetext{
* Corresponding author. Tel.: +1 601634 3593; fax: +1 6016344002

E-mail address: kurt.a.gust@erdc.usace.army.mil (K.A. Gust).
}

RDX has been observed to accumulate in a variety of aquatic invertebrates and vertebrates exposed to water containing RDX (Houston and Lotufo, 2005; Talmage et al., 1999). Observed effects of RDX exposure in the ecotoxicological model species fathead minnow include lethality, impaired growth and reduced reproduction (Burton et al., 1994; Talmage et al., 1999). Evidence that the central nervous system is the primary toxicological target for RDX include observation of RDX-induced convulsions in rats (Meyer et al., 2005), miniature swine (Schneider et al., 1977), mice (Dilley et al., 1978), Northern bobwhite (Johnson et al., 2007; Quinn et al., 2009; Gust et al., 2009) and humans (Stone et al., 1969; Woody et al., 1986). Neurotoxicogenomic investigations in rat and Northern bobwhite indicate that RDX-induced seizures are likely driven by various impacts on genes and pathways involved in the neurophysiology of brain tissue (Bannon et al., 2009; Gust et al., 2009). 
Given that RDX may accumulate in surface waters, the potential for impacts on CNS in fish is of concern. The purpose of our study was to screen for the effects of RDX exposure on transcript expression in brain tissues of the ecotoxicological fish model (fathead minnow) and develop a comprehensive suite of hypothetical mechanisms of action underlying the observed toxicological impacts caused by RDX.

Fathead minnow was selected for this investigation due to its status as the predominant fish model for investigating the acute and chronic toxicity of chemical contaminants (Ankley and Villeneuve, 2006; US EPA, 2002a,b) and its emergence as a robust model for conducting toxicogenomic investigations (Garcia-Reyero et al., 2009a,b, 2008; Larkin et al., 2007; Ankley and Villeneuve, 2006; Wintz et al., 2006). Our study incorporated the development of a brain-tissue based de novo cDNA library for fathead minnow enriched for transcripts differentially expressed in response to the MCs, RDX and TNT. The cDNA library was sequenced, functionally annotated and transitioned to microarray for use in transcript expression analyses. We utilized the microarrays to assess the effects of RDX exposure on transcript expression in fathead minnow followed by validation with reverse transcriptase quantitative polymerase chain reaction (RT-qPCR). A broad interpretation of the expression results was utilized to describe all plausible mechanisms of action by which RDX elicited toxicological impacts. The genomic tools and resultant knowledge regarding impacts of RDX exposure on fathead minnow health can contribute directly to adaptive management of military installations, providing environmental quality assurance.

\section{Materials and methods}

\subsection{Study design}

Two sets of MC exposures were conducted during the execution of this study. First, 200 sub-adult fathead minnows (20 weeks old) were divided among control, $10 \mu \mathrm{M}$ RDX and $10 \mu \mathrm{M}$ TNT treatment conditions (nominal concentrations) and exposed for 4 days. This set of fish was utilized as the source of mRNA transcripts for cDNA library and custom microarray construction. After exposure, the fish were sacrificed by cervical dislocation (separating the spinal cord from the brainstem) and brain tissues were excised and transferred to RNA Later for RNA fixation following manufacturer's recommendations (Applied Biosystems, Foster City, CA). A second RDX exposure was designed to investigate the gross-level toxicological effects of RDX on sub-adult fathead minnows (20 weeks old) and determine the effects of RDX on transcript expression in fathead minnow brain tissue. The 20 week old fish were utilized to insure that each biological replicate ( 1 individual) was large enough to provide sufficient RNA from brain tissue for microarray analysis yet still represent juvenile fish that had not begun sexual dimorphism. Fathead minnows were exposed to RDX in a 10 days concentration-series experiment $(0.625,1.25,2.5,5.0$, or $10 \mathrm{mg} / \mathrm{L})$ which included an acetone-spike control $(0.1 \%$ acetone, i.e. $1 \mathrm{ml} / \mathrm{L})$ to match the volume of acetone used to deliver all RDX spikes. Each experimental treatment included 8 fish (48 total fish) and endpoints included mortality, total weight and transcript expression in brain tissue. Assumptions of ANOVA were not met regarding the mortality dataset, therefore a Kruskal-Wallis one-way ANOVA on ranks was utilized to test RDX effects on mortality. Standard parametric one-way ANOVA was utilized to test effects of RDX on fathead minnow total weight. Brain tissues were collected from 4 randomly selected fish per experimental treatment. Brain tissues were fixed in RNA Later as described above keeping biological replicates separated.

\subsection{Bioassay water quality}

Water quality parameters including temperature, dissolved oxygen, $\mathrm{pH}$, ammonia concentration, hardness, and alkalinity were measured at the initiation and termination of each bioassay. During the bioassays, temperature, dissolved oxygen, and $\mathrm{pH}$ were measured on days 1, 2 and then every other day until bioassay termination.

\subsection{RNA extraction}

RNeasy ${ }^{\circledR}$ Mini RNA extraction kits (Qiagen, Valencia, CA) were used for total RNA extractions. RNA quality was assessed using an Agilent 2100 Bioanalyzer (Agilent Technologies, Santa Clara, CA) with RNA 6000 Nano LabChips ${ }^{\circledR}$ RNA. Only samples with a $28 \mathrm{~S} / 18 \mathrm{~S} \geq 1.4$ and RNA integrity number $\geq 6$ were used for downstream applications. The majority of RNA samples greatly exceeded these minimum requirements. Total RNA was utilized for cDNA library construction, microarray analysis and RT-qPCR.

\section{4. cDNA library construction}

Suppression-subtractive hybridization (SSH-PCR) was used (Diatchenko et al., 1996) to construct the cDNA library for fathead minnow brain exposed to RDX and TNT. mRNA samples were pooled for RDX and TNT exposures and forward and reverse subtracted against a pooled sample of mRNA from controls to produce libraries enriched for up-regulated and down-regulated transcripts (see Supplementary methods for details). The final SSH-PCR cDNA library consisted of 2304 forward- and 1824 reverse-subtracted clones, respectively for a total of 4128 clones.

\subsection{Microarray construction}

The 4128 cloned inserts from the SSH cDNA library were isolated and purified as described in (Pirooznia et al., 2007) and spotted onto Ultra GAPS-coated microarray slides (Corning Inc., Corning, NY). Spotted cDNAs were immobilized on the chip surface by applying $300 \mathrm{~mJ}$ of UV radiation in a Stratagene ${ }^{\mathrm{TM}}$ UV Stratalinker 2400 (Agilent Technologies). All slides were stored in a darkened desiccation chamber thereafter, and pre-treated as described in Supplementary methods prior to microarray hybridizations.

\section{6. cDNA sequencing, clustering and annotation}

All cDNAs represented on the microarray (4128) were sequenced using an ABI 3100 Genetic Analyzer (Applied Biosystems, Foster City, CA) following the ABI PRISM ${ }^{\circledR}$ Big Dye ${ }^{\mathrm{TM}}$ Terminator reaction protocol. Sequences were vector trimmed, quality assessed and assembled into clusters of contiguous overlapping sequences (contigs) and individual sequences having no significant overlap with other sequences (singletons) as described in Pirooznia et al. (2007). Identities of cDNAs were established by searching all six potential reading frames of each unique sequence against the National Center for Biotechnology Information (NCBI) non-redundant protein database using blastx (www.ncbi.nlm.nih.gov). An expectation $(E)$ value of $\leq 10^{-5}$ was designated as a significant match between fathead minnow transcripts and the best NCBI database match. Putative functions to the unique sequences were assigned employing blast2go (Conesa and Gotz, 2008), GOTM (Zhang et al., 2004), GOfetcher (Pirooznia et al., 2008) and GOstat (Beissbarth and Speed, 2004) to extract the gene ontology (GO) hierarchical terms of homologous genes from the protein databases. GO and functional classification was conducted for all high quality sequences following Pirooznia et al. (2007). 


\begin{tabular}{|c|c|c|c|c|c|c|}
\hline $\begin{array}{c}10 \text { Day } \\
\text { RDX }\end{array}$ & \begin{tabular}{|l} 
Solvent \\
Control
\end{tabular} & \begin{tabular}{|c}
$\begin{array}{c}0.625 \\
(\mathrm{mg} / \mathrm{L})\end{array}$ \\
\end{tabular} & $\begin{array}{c}2.5 \\
(\mathrm{mg} / \mathrm{L}) \\
\end{array}$ & $\begin{array}{c}5 \\
(\mathrm{mg} / \mathrm{L})\end{array}$ & $\begin{array}{c}10 \\
(\mathrm{mg} / \mathrm{L})\end{array}$ & $\begin{array}{r}1.25^{*} \\
(\mathrm{mg} / \mathrm{L})\end{array}$ \\
\hline $\operatorname{Rep} 1$ & c1 & d1a & d2a & d3a & $\mathrm{d} 4 \mathrm{a}$ & d5a \\
\hline $\operatorname{Rep} 2$ & $\mathrm{c} 2$ & $\mathrm{~d} 1 \mathrm{~b}$ & $d 2 b$ & $d 3 b$ & $d 4 b$ & $d 5 b$ \\
\hline $\operatorname{Rep} 3$ & c3 & d1c & d2c & $d 3 c$ & $d 4 c$ & $d 5 c$ \\
\hline
\end{tabular}

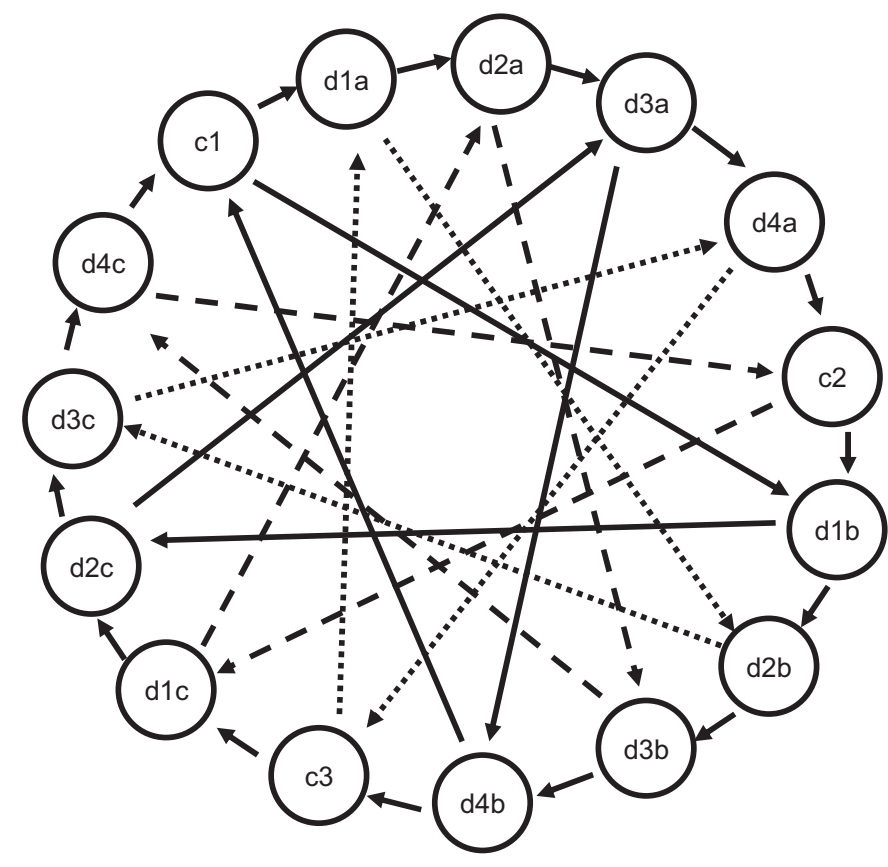

Fig. 1. Experimental design for the microarray experiment. A balanced-interwoven loop design was utilized to investigate the effects of a 10 day RDX exposure on transcript expression in fathead minnow brain tissues in a microarray experiment. Experimental groups included, solvent controls and RDX doses each including 3 biological replicates. Each arrow represents a unique 2-color hybridization where arrow heads and tails point at the biological samples included in each respective hybridization. Arrow heads point at the biological replicate labeled with the A647 dye and arrow tails point at the biological replicate labeled with Cy3 yielding two complete sets of dye swaps and 4 technical replicates per sample for a total of 30 microarray hybridizations.

\subsection{Microarray experimental designs}

Microarray experiments were conducted using a balanced interwoven-loop design (Fig. 1) which has been identified to be the most statistically robust design available for 2-color microarray analysis (Churchill, 2002). The experiment compared controls with $0.625,2.5,5$ and $10 \mathrm{mg} / \mathrm{L}$ RDX-exposed fish with each condition including 3 biological replicates. Due to limited availability of custom-printed microarrays for hybridizations, the $1.25 \mathrm{mg} / \mathrm{L}$ treatment was omitted from the experimental design because it was determined to be the most expendable. Hybridizations included four technical replicates and two dye swaps per biological replicate resulting in a total of 30 microarrays assayed.

\subsection{Microarray hybridization and analysis}

Two-color microarray hybridizations were conducted as described in the Supplementary methods. Microarrays were scanned at $5 \mu \mathrm{m}$ resolution using a VersArray Chipreader ${ }^{\mathrm{TM}}$ (BioRad Laboratories Inc. Hercules, CA) and data extracted using VersArray Software, Version 4.5 (Bio-Rad Laboratories Inc.). Grids were manually fit to microarray spots for each image file and both positive and negative controls were flagged prior to spot analysis. Data for which the spot intensity was less than the background intensity plus $2 \times$ the background standard deviation for $\geq 1$ signal channel were excluded from the statistical analysis. Summary data consisted of LOWESS-normalized Cy3:A647 ratio values calculated using background-normalized median-signal intensities.

The statistical analysis was conducted using Bayesian Analysis of Gene Expression Levels (BAGEL) software version 3.62 (Townsend and Hartl, 2002). Non-overlapping 97.5\% confidence intervals (C.I.) among treatments was established $a$ priori as statistically significant difference in expression among treated and control groups. Fold change values are reported as mean treatment expression relative to mean control expression in a $\log _{2}$ format.

\subsection{Reverse-transcriptase, quantitative polymerase chain reaction $(R T-q P C R)$}

Microarray results were validated by RT-qPCR utilizing 27 primer sets (Table S1) to investigate 24 unique transcript targets in addition to three regulatory "control" transcripts as recommended in Filby and Tyler (2007). Transcript expression levels were examined using DNase (Qiagen) treated total RNA from all biological replicates used in microarray hybridizations plus one additional biological replicate for each condition (4 biological replicates per condition, see Supplementary text for molecular methods). The SDS 2.2 software package (Applied Biosystems, Foster City, CA) was utilized to resolve RT-qPCR data and the $\Delta \triangle C T$ method used to quantify results as recommended by the developer. Assumptions inherent in the $\Delta \Delta C T$ analysis were observed to be met sufficiently insuring accuracy of downstream analysis. All regulatory controls were observed to be unaffected by RDX treatment. Ribosomal protein 18 (rp18) was selected as the internal normalizer for relative quantification (RQ) because it had the least variability in RQ and a threshold cycle $(\mathrm{Ct})$ value near the median of all RT-qPCR reactions. Fold change values were calculated using relative quantification (RQ) results where values represent transcript expression in RDXtreated fish relative to control fish. The $99 \%$ confidence interval (99\% C.I.) was calculated around the mean relative expression for each RDX concentration. Confidence intervals that did not include unity were considered differentially expressed relative to controls as described in Rawat et al. (2010).

\section{Results}

\subsection{Effects of RDX on survivorship and fish total mass}

RDX caused significant mortality $(P=0.005)$ and caused a non-significant $(P=0.052)$, but potentially biologically significant decrease in total mass in sub-adult fathead minnow at $10 \mathrm{mg} / \mathrm{L}$ (Fig. 2). Water quality parameters remained within the limits of acceptability (US EPA, 2002a) throughout both the toxicological bioassay and the exposure to generate tissue for cDNA library construction (Table S2).

\section{2. cDNA sequencing and annotation summary}

The sequencing and annotation effort conducted for fathead minnow investigated all 4128 sequences spotted on the microarray which yielded 3454 quality-assured sequence reads after vector and adaptor trimming and end clipping (Fig. 3). Of these quality-assured reads, 1590 had no significant overlap with any sequences within the sequence set (singletons) representing unique sequences. The remaining 1864 sequences clustered into 640 individual contiguous overlapping sequences (contigs) for a total of 2230 unique sequences represented on the microarray. Contigs and singletons were queried against Genbank yielding a total of 945 significant blastx matches $\left(E \leq 10^{-5}\right)$ that were used for GO and molecular pathway annotation. All 3454 quality-assured sequences were submitted to GenBank dbEST (GenBank accession numbers GT145412 to GT148913) which can be accessed at: 

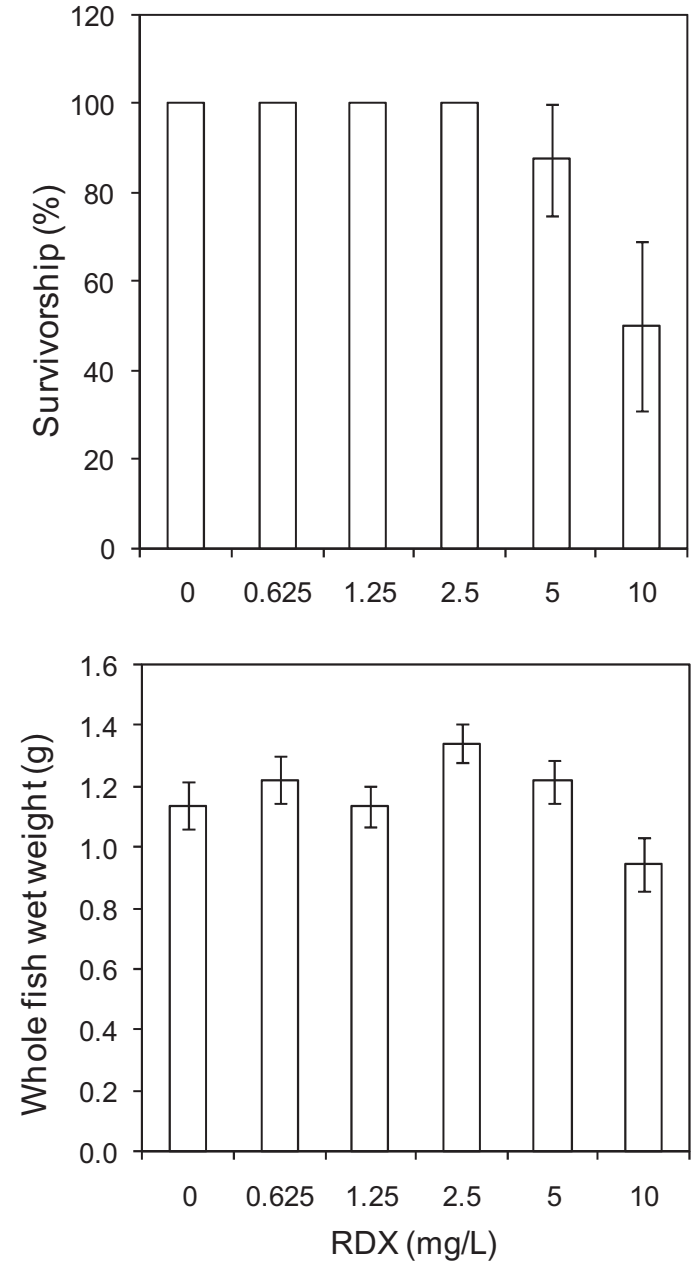

Fig. 2. Effect of RDX on fathead minnow survival and total wet weight. Bars represent means and error bars represent standard error. For the survival test $n=8$ for all treatments. The test of wet weight had $n=8$ for all treatments except for the 5 and $10 \mathrm{mg} / \mathrm{L}$ treatments which had $n=7$ and $n=4$, respectively.

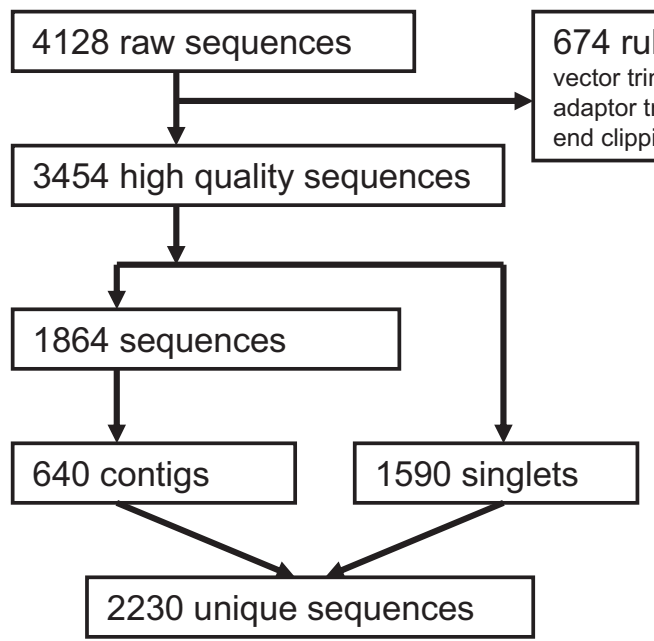

Fig. 3. Summary of steps involved in processing the sequence data for the fathead minnow cDNA library.
Table 1

Summary of microarray analysis investigating effects of RDX exposure on transcript expression in fathead minnow brain tissue. The inset figure provides a Venn diagram to compare microarray targets differentially expressed in common among RDXexposure concentrations $(\mathrm{mg} / \mathrm{L})$.

\begin{tabular}{lc}
\hline Microarray Properties & \\
\hline Total microarray spots & 4224 \\
Total buffer blanks & 36 \\
Total fathead minnow cDNA targets on array & 4188 \\
Targets contributed to analysis & 1814 \\
\hline$\%$ of targets contributed to analysis & 43.3 \\
Statistical Analysis of Microarray Data & $\mathbf{1 5 4}$ \\
\hline \# of significant targets (RDX vs Control) & $\mathbf{8 . 5}$ \\
\% of targets were significant & 114 \\
Bioinformatics Summary of Significant Targets & 12 \\
\hline Total \# targets with sequence data available & 33 \\
Targets with no match to known sequences & 69 \\
Targets with non-significant match to known sequences (E value > 10^-5) & $\mathbf{4 4 . 8}$ \\
Total significant matches to known sequences & $\mathbf{4 4}$ \\
\hline \% of Significant Targets Characterized & \\
Total \# of unique accession IDs within significant sequence matches & \\
\hline
\end{tabular}

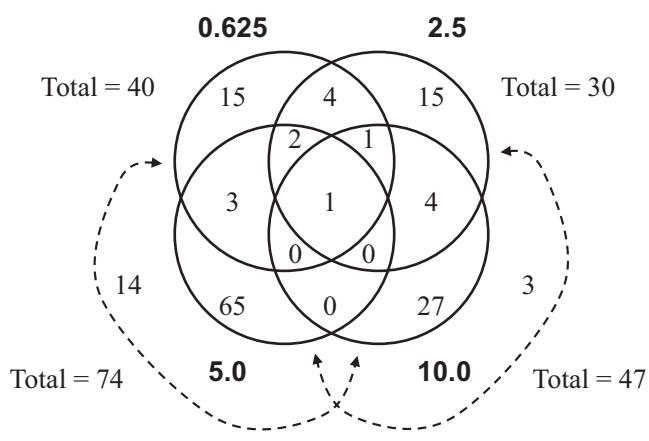

http://www.ncbi.nlm.nih.gov/sites/entrez?db=nucleotide\&cmd= search\&term=GT148876.

\subsection{Impact of $R D X$ exposure on transcription}

Microarray analysis indicated that $43.3 \%$ of all cDNA targets had sufficient data to perform a statistical test of differential transcript expression (Table 1). Exposure to RDX elicited significant differential expression of 154 microarray targets (8.5\% all targets contributing to the analysis). Further, $70.8 \%$ of the targets indicated differential expression at $\geq 2$-fold difference compared to controls and $76.2 \%$ of all $97.5 \%$ confidence intervals had values within $20 \%$ of the mean which indicates low variance (Table S3). Sixty-nine of the significant differentially expressed targets had significant blastx identities providing expressed sequence tags (ESTs) by which we established putative transcript identities. The ability to leverage the full suite of differentially expressed transcripts is central to understanding the global response to RDX exposure. Unfortunately, it is very difficult to contextualize the contribution of differentially expressed transcripts that have no known identity (i.e. no information for the coded protein product). Therefore, we concentrated our efforts and resources on gaining knowledge from transcripts that had protein-coding information. Further, all transcript sequences are available at the GEO website (see address below), therefore the potential to describe the unidentified transcripts may be possible as genome databases become more robust.

A total of 44 unique transcript identities were observed that encompassed a large breadth of functions (Table 2, Table S3). Of the 44 unique transcript identities observed, 16 transcript identities had associated GO terms derived from zebrafish (Danio rerio) or human (Homo sapiens). GO terms were investigated within the 3 main categories of the GO: cellular component, molec- 
Table 2

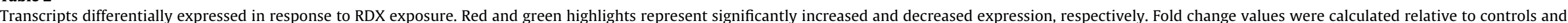

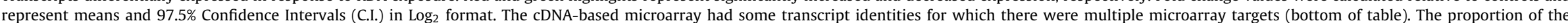

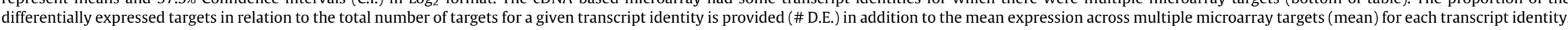

\begin{tabular}{|c|c|c|c|c|c|c|c|c|c|c|c|c|c|c|c|}
\hline & \begin{tabular}{|c|} 
Fold \\
Change \\
0.625 \\
$\mathrm{mg} / \mathrm{L}$ \\
\end{tabular} & $\begin{array}{r}97.5 \% \\
0.625\end{array}$ & $\begin{array}{l}\text { C.I. } \\
\mathrm{ng} / \mathrm{L}\end{array}$ & $\begin{array}{c}\text { Fold } \\
\text { Change } \\
2.5 \\
\mathrm{mg} / \mathrm{L} \\
\end{array}$ & $\begin{array}{r}97.5 \% \\
2.5 \mathrm{n}\end{array}$ & & $\begin{array}{c}\text { Fold } \\
\text { Change } \\
5.0 \\
\mathrm{mg} / \mathrm{L} \\
\end{array}$ & $\begin{array}{l}97.5 \% \\
5.0 \mathrm{~m}\end{array}$ & $\begin{array}{l}\text { C.I. } \\
\text { g/L }\end{array}$ & $\begin{array}{c}\text { Fold } \\
\text { Change } \\
10.0 \\
\mathrm{mg} / \mathrm{L} \\
\end{array}$ & $\begin{array}{l}97.5^{\circ} \\
10.0\end{array}$ & C.I. & $\begin{array}{c}\text { Accession } \\
\text { Version \# }\end{array}$ & Gene Symbol & Expressed Sequence Tag \\
\hline & -1.06 & -1.38 & -0.52 & 1.58 & 1.52 & & 0.21 & 0.26 & -0.03 & 0.80 & 0.85 & 0.67 & AAH66505.1 & abcf2 & Abcf2 protein \\
\hline & -1.03 & -1.10 & -0.94 & -0.95 & -1.15 & -0.78 & -0.97 & -1.11 & -0.77 & -0.81 & -0.89 & -0.71 & AAO59418.1 & PPP3R1 & calcineurin B \\
\hline & 0.35 & 0.11 & 0.51 & -1.03 & -1.26 & -0.79 & -0.63 & -0.79 & -0.50 & -0.44 & -0.48 & -0.42 & XP 708748.1 & LOC567858 & cornifelin isoform 2 PREDICTED \\
\hline & -0.10 & -0.10 & -0.10 & -0.07 & -0.07 & -0.08 & -0.45 & -0.45 & -0.45 & 0.01 & 0.02 & 0.00 & AAS̄ 68238.1 & CYTB & cytochrome b \\
\hline & -0.21 & -0.22 & -0.18 & -0.25 & -0.35 & -0.19 & -0.90 & -1.08 & -0.72 & -0.19 & -0.23 & -0.12 & NP_387474.1 & cox1 & cytochrome c oxidase subunit I \\
\hline & 0.77 & 0.95 & 0.56 & 1.33 & 1.62 & 1.11 & 2.82 & 3.38 & 2.10 & 0.30 & 0.55 & 0.18 & $\mathrm{NP}_{-}^{-} 818829.1$ & $\operatorname{cox} 2$ & cytochrome c oxidase subunit II \\
\hline & 0.38 & 0.26 & 0.46 & 0.93 & 0.48 & 1.11 & 1.55 & 1.56 & 1.55 & 0.48 & 0.50 & 0.46 & СА̄̈73620.1 & Eef1a3 & eukaryotic translation elongation factor 1 alpha-like 3 \\
\hline & -0.82 & -0.87 & -0.72 & -0.61 & -0.75 & -0.45 & -1.48 & -1.64 & -1.32 & -0.44 & -0.49 & -0.37 & XP_696130.1 & LOC567738 & F-box only protein 21 isoform 2 PREDICTED \\
\hline & -0.10 & -0.15 & -0.07 & 0.43 & 0.43 & 0.41 & 0.20 & 0.22 & 0.16 & 0.72 & 0.75 & 0.67 & NP_878286.1 & glulb & glutamine synthetase 2 \\
\hline & & & & 0.08 & 0.05 & 0.29 & 0.65 & 0.46 & 0.66 & 0.74 & 0.68 & 0.70 & AAO 43731.1 & hspa8 & heat shock cognate $70 \mathrm{kDa}$ protein \\
\hline & -0.30 & -0.33 & -0.30 & -0.16 & -0.22 & -0.11 & -0.75 & -0.85 & -0.66 & 0.25 & 0.24 & 0.27 & NP_998799.1 & & hypothetical protein LOC336492 \\
\hline & 0.13 & 0.12 & 0.13 & 0.49 & 0.51 & 0.47 & 0.22 & 0.22 & 0.21 & 0.44 & 0.44 & 0.43 & NP_998350.1 & & hypothetical protein LOC406464 \\
\hline & -1.65 & -1.83 & -1.40 & -1.36 & -1.57 & -1.03 & -1.00 & -1.18 & -0.68 & -1.84 & -2.09 & -1.53 & NP_-998600.1 & & hypothetical protein LOC406744 \\
\hline & -0.30 & -0.33 & -0.30 & -0.54 & -0.62 & -0.45 & -0.83 & -0.93 & -0.71 & 0.25 & 0.22 & 0.26 & NP_001002111.1 & & hypothetical protein LOC415201 \\
\hline & -0.90 & -1.24 & -0.79 & -1.00 & -1.08 & -0.84 & -0.43 & -0.44 & -0.35 & -1.79 & -1.92 & -1.60 & NP 001002163.1 & & hypothetical protein LOC415253 \\
\hline & -0.85 & -1.07 & -0.53 & -2.39 & -2.62 & -1.89 & -0.25 & -0.22 & -0.19 & -0.23 & -0.12 & -0.25 & XP 700929.1 & & hypothetical protein XP 695837, partial PREDICTED \\
\hline & 0.84 & 0.79 & 0.80 & 1.35 & 1.36 & 1.39 & 2.58 & 2.90 & 2.08 & 1.30 & 1.53 & 1.04 & $\mathrm{P} 1 \overline{8} 520$ & krt8 & Intermediate filament protein ON3 \\
\hline & 0.79 & 0.89 & & 0.51 & 0.61 & 0.42 & -0.17 & -0.18 & -0.15 & -0.07 & -0.12 & 0.01 & AAH63967.1 & idh2 & Isocitrate dehydrogenase 2 (NADP+), mitochondrial \\
\hline & -0.22 & -0.26 & -0.16 & -0.10 & -0.33 & 0.09 & -1.82 & -2.18 & -1.35 & 0.09 & -0.03 & 0.15 & AAA21578.1 & si:ch211-251b21.1 & kainate receptor alpha subunit \\
\hline & -1.36 & -1.49 & -1.07 & -0.78 & -0.90 & -0.46 & -0.11 & -0.23 & 0.00 & 0.17 & 0.19 & 0.12 & NP_956241.1 & mdh1a & malate dehydrogenase 1a, NAD (soluble) \\
\hline & -0.18 & -0.19 & -0.15 & -0.35 & -0.39 & -0.31 & -0.69 & -0.76 & -0.63 & -0.47 & -0.50 & -0.45 & AĀ 65888.1 & Pgk1 & Pgk1 protein \\
\hline & 0.95 & 0.93 & 0.73 & 1.67 & 1.62 & 1.38 & 2.27 & 2.46 & 1.80 & 0.53 & 0.64 & 0.31 & Q08470 & Dpsell(2)gl & Protein lethal(2) giant larvae (P127) \\
\hline & -0.06 & -0.11 & -0.02 & 0.91 & 0.79 & 0.95 & 1.61 & 1.64 & 1.49 & 0.34 & 0.35 & 0.31 & AAP06225.1 & zgc:77235 & ribosomal protein SIMILAR \\
\hline & -1.46 & -1.70 & -1.16 & -1.23 & -1.48 & -0.97 & -0.80 & -0.90 & -0.58 & -1.90 & -2.10 & -1.61 & CAJ17176.1 & LOC100117715 & ribosomal protein S8e \\
\hline & 0.28 & 0.30 & 0.31 & 1.87 & 1.88 & & 2.21 & 2.27 & 1.98 & 0.57 & 0.62 & 0.55 & AAT01083.1 & LOC724793; UBC & ubiquitin-conjugating enzyme PUTATIVE \\
\hline & -1.77 & -2.08 & -1.31 & -0.68 & -0.74 & -0.56 & -0.21 & -0.14 & -0.27 & -0.20 & -0.11 & -0.29 & BAB28327.1 & & unnamed protein product \\
\hline & -0.87 & -1.08 & -0.66 & -1.35 & -1.92 & -0.87 & -0.99 & -1.49 & -0.49 & -0.40 & -0.53 & -0.29 & CAG00560.1 & & unnamed protein product \\
\hline & -0.25 & -0.27 & -0.22 & -0.34 & -0.40 & -0.28 & 0.70 & 0.61 & 0.75 & 0.34 & 0.32 & 0.35 & CAG07651.1 & & unnamed protein product \\
\hline & & & & 1.48 & 1.53 & 0.88 & 0.21 & 0.34 & 0.00 & 0.22 & 0.30 & 0.12 & CAG07948.1 & & unnamed protein product \\
\hline & -0.78 & -0.87 & -0.72 & -0.52 & -0.64 & -0.42 & 1.82 & 2.17 & 1.37 & -0.25 & -0.22 & -0.19 & AAH90751.1 & & unnamed protein: Im:6912380 protein \\
\hline & 0.09 & 0.09 & 0.09 & -0.05 & -0.11 & 0.02 & -0.85 & -1.01 & -0.68 & 0.12 & 0.06 & 0.16 & AAH59527.1 & Snrpb2 & unnamed protein: LOC402896 protein \\
\hline & 2.42 & 2.32 & 1.73 & 2.81 & 3.64 & & 3.18 & 4.01 & 2.00 & 0.35 & 0.70 & 0.09 & AAW25017.1 & & unnamed protein: SJCHGC00366 protein \\
\hline & 0.23 & 0.09 & 0.21 & 1.48 & 1.28 & 1.33 & 2.48 & 2.78 & 1.90 & 0.74 & 0.91 & 0.50 & AAW26726.1 & & unnamed protein: SJCHGC09063 protein \\
\hline & 0.44 & 0.36 & 0.49 & 1.34 & 1.19 & 1.34 & 1.97 & 1.99 & 1.78 & 0.37 & 0.38 & 0.37 & CAA17812.1 & Gpd3 & unnamed protein: SPBC354.12 \\
\hline & -0.11 & -0.13 & -0.06 & -0.65 & -0.63 & -0.63 & -0.46 & -0.42 & -0.46 & -0.14 & -0.11 & -0.15 & AAH55190.1 & & unnamed protein: Unknown (protein for MGC:63657) \\
\hline & -1.77 & -1.98 & -1.37 & -1.55 & -1.82 & -1.24 & -1.02 & -1.13 & -0.70 & -2.24 & -2.43 & -1.83 & AAH55570.1 & vtnb & Vtn protein \\
\hline mean & -1.55 & -1.68 & -1.31 & -1.35 & -1.55 & -1.06 & $\overline{-0.82}$ & -1.03 & -0.50 & -2.31 & -2.64 & -1.81 & AAH76356.1 & ba2 & Ba2 globin, like \\
\hline D.E. & 4 of 9 & & & 1 of 9 & & & 0 of 9 & & & 8 of 9 & & & & & \\
\hline mean & 0.13 & 0.14 & 0.12 & -0.09 & -0.12 & -0.05 & -0.97 & -1.07 & -0.85 & -0.17 & -0.21 & -0.12 & XP 874377.1 & CALM3 & calmodulin 1 PREDICTED \\
\hline D.E. & 0 of 2 & & & 0 of 2 & & & 2 of 2 & & & 0 of 2 & & & & & \\
\hline mean & -0.24 & -0.25 & -0.22 & -0.25 & -0.27 & -0.21 & -0.58 & -0.60 & -0.54 & -0.28 & -0.28 & -0.27 & AAH67585.1 & DDx5 & Ddx5 protein \\
\hline D.E. & 0 of 2 & & & 0 of 2 & & & 2 of 2 & & & 0 of 2 & & & & & \\
\hline mean & -1.40 & -1.51 & -1.21 & -1.35 & -1.45 & -1.16 & -0.52 & -0.53 & -0.39 & -2.04 & -2.21 & -1.72 & P02016 & hbaa1 & Hemoglobin alpha subunit (Hemoglobin alpha chain) (Alpha-globin) \\
\hline D.E. & 0 of 2 & & & 0 of 2 & & & 0 of 2 & & & 2 of 2 & & & & & \\
\hline mean & -1.58 & -1.78 & -1.29 & -1.71 & -2.16 & -1.27 & -0.46 & -0.53 & -0.28 & -2.04 & -2.20 & -1.70 & P02140 & ba2 & Hemoglobin beta subunit (Hemoglobin beta chain) (Beta-globin) \\
\hline D.E. & 6 of 12 & & & 1 of 12 & & & 0 of 12 & & & 12 of 12 & & & & & \\
\hline mean & -1.20 & -1.34 & -1.00 & -1.06 & -1.44 & -0.72 & -2.47 & -2.90 & -2.02 & -0.71 & -0.86 & -0.56 & XP_696056.1 & LOC567663 & neurogranin PREDICTED \\
\hline D.E. & 2 of 2 & & & 1 of 2 & & & 2 of 2 & & & 0 of 2 & & & & & \\
\hline mean & 0.58 & 0.59 & 0.57 & 1.46 & 1.39 & 1.43 & 2.07 & 2.17 & 1.84 & & 0.62 & 0.49 & AAP06478.1 & Rpl7 & ribosomal protein SIMILAR \\
\hline D.E. & 0 of 2 & & & 0 of 2 & & & 2 of 2 & & & 0 of 2 & & & & & \\
\hline mean & -0.12 & -0.15 & -0.10 & -0.21 & -0.28 & -0.15 & -0.85 & -1.00 & -0.73 & 0.01 & -0.05 & 0.06 & AAH86710.1 & ywhab1 & Wu:fb80c08 protein \\
\hline D.E. & 0 of 2 & & & 0 of 2 & & & 2 of 2 & & & 0 of 2 & & & & & \\
\hline
\end{tabular}




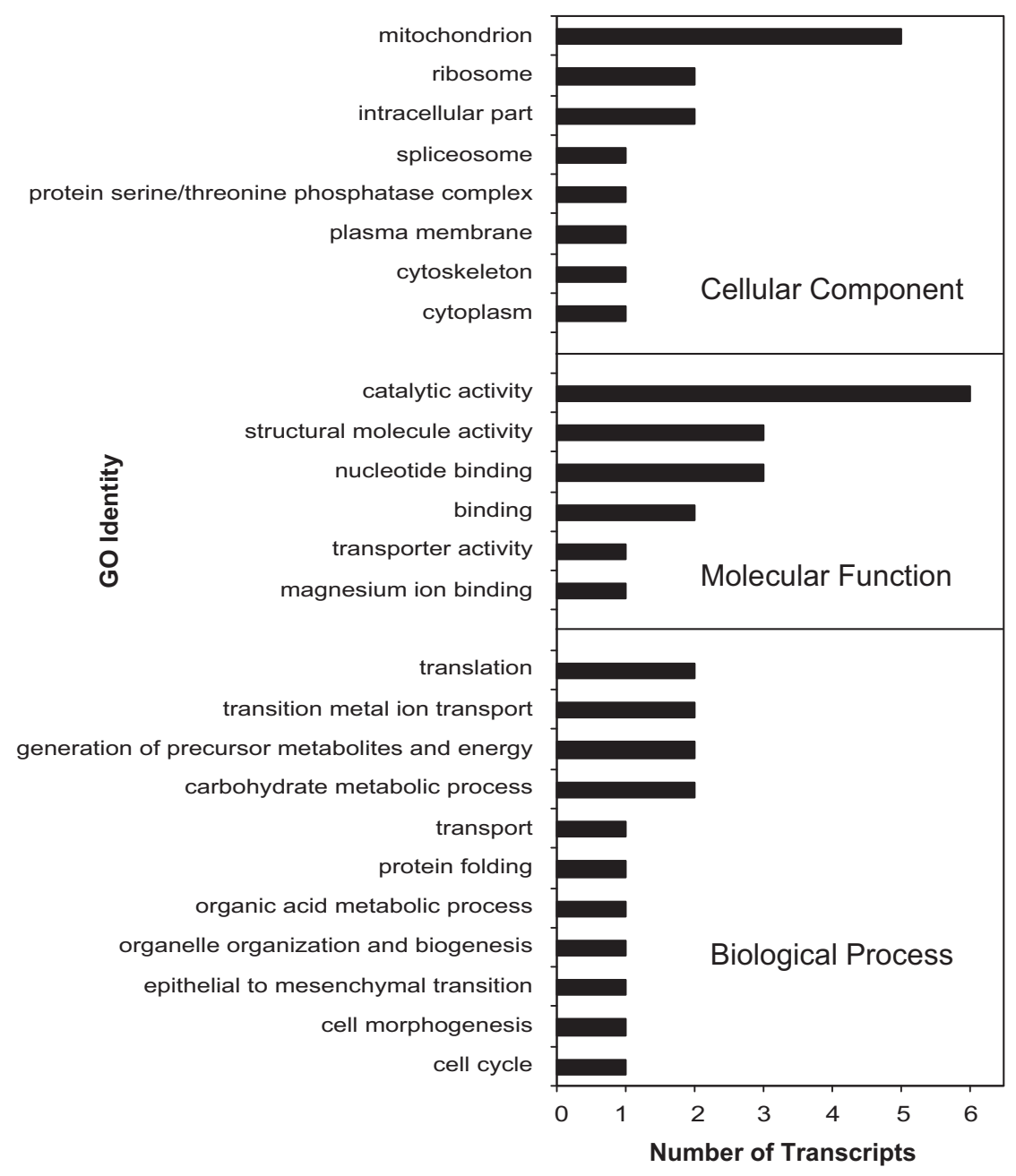

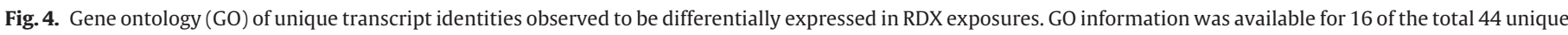

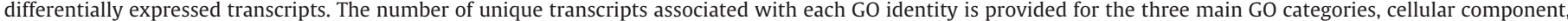

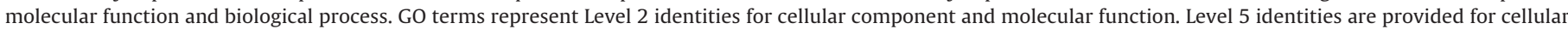
component.

ular function and biological process (Fig. 4). The mitochondria were observed to be the most predominantly affected element among cellular components. Regarding molecular functions, transcript identities with products involved in catalytic activity were predominantly affected as well as elements involved in structuralmolecule activity and nucleotide binding. Biological processes affected by RDX had a relatively broad distribution among GO categories including: translation, transition metal ion transport, generation of precursor metabolites and energy as well as others processes (Fig. 4). Raw data and metadata for the microarray experiment can be viewed under the GEO accession \#GSE21153 http://www.ncbi.nlm.nih.gov/geo/query/acc.cgi?acc=GSE21153.

\subsection{Pathway analysis of transcripts affected by RDX}

Pathway analysis was conducted utilizing the 44 unique transcript identities observed to be affected by RDX of which 11 were identified as components of Kyoto Encyclopedia of Genes and Genomes (KEGG) metabolic pathways (Table 3). Twentyeight unique metabolic pathways were observed to have elements affected by RDX at the transcriptional level. Five pathways had 2 elements affected in the same pathway including: calcium signaling pathway, citrate cycle, oxidative phosphorylation, reductive carboxylate cycle and a ribosome pathway.

\subsection{Validation of microarray results using $R T-q P C R$}

Results of the RT-qPCR analysis confirmed microarray results for $54.2 \%, 62.5 \%$ and $87.5 \%$ of targets for the $0.625,2.5$ and $10 \mathrm{mg} / \mathrm{L}$ RDX concentrations, respectively (Table 4). Further, significant positive correlations were observed between transcript expression among RT-qPCR and microarray results (Table 4) indicating reasonable agreement among analytical techniques. Significant differential expression was confirmed for a variety of transcript targets including genes encoding Ba2 globin (ba2), glutamine synthetase 2 (glulb), hemoglobin alpha subunit (hbaa1), isocitrate dehydrogenase 2 (idh2), neurogranin (LOC567663) and ubiquitinconjugating enzyme (UBC).

\section{Discussion}

We have isolated and sequenced 4128 clone-based cDNAs from a fathead minnow brain library enriched for transcripts that were responsive to RDX and TNT exposure. These cDNAs were used to construct a custom cDNA microarray that was subsequently applied to assess the impact of RDX on transcriptional profiles in fathead minnow brains. The sequencing and annotation of the de novo cDNA library provided a useful characterization of transcripts expressed in brain tissue of fathead minnow. The fathead 
Table 3

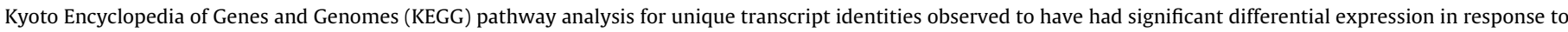

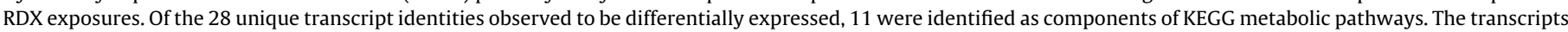

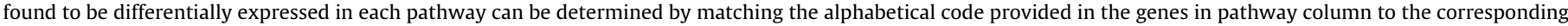
letters provided in the gene IDs column.

\begin{tabular}{|c|c|c|c|c|c|}
\hline Metabolic pathway (KEGG) & KEGG pathways & Genes in pathway & Gene IDs & Gene symbol & Gene name \\
\hline $\begin{array}{l}\text { Antigen processing and } \\
\text { presentation }\end{array}$ & hsa04612 & $\mathrm{E}$ & A & CALM3 & Calmodulin LOC456153 \\
\hline Apoptosis & hsa04210 & I & $\mathrm{B}$ & $\mathrm{COX} 2$ & Cytochrome oxidase subunit II \\
\hline Axon guidance & hsa04360 & I & $\mathrm{C}$ & СYТВ & Cytochrome B \\
\hline Calcium signaling pathway & ptr04020 & A, I & $\mathrm{D}$ & glulb & $\begin{array}{l}\text { Glutamate-ammonia ligase } \\
\text { (glutamine synthase) B }\end{array}$ \\
\hline Carbon fixation & dre00710 & $\mathrm{H}$ & $\mathrm{E}$ & hspa8 & Heat shock 70 kda Protein 8 \\
\hline Cell communication & dre01430 & G & $\mathrm{F}$ & idh2 & $\begin{array}{l}\text { Isocitrate dehydrogenase } 2 \\
(\mathrm{NADP}+) \text {, mitochomdrial }\end{array}$ \\
\hline Citrate cycle (TCA cycle) & hsa00020 & $\mathrm{F}, \mathrm{H}$ & G & krt8 & Keratin 8 \\
\hline Glutamate metabolism & dre00251 & $\mathrm{D}$ & $\mathrm{H}$ & mdh1a & WU:FJ05B08 \\
\hline Glutathione metabolism & hsa00480 & $\mathrm{F}$ & I & PPP3R1 & $\begin{array}{l}\text { Protein phosphatase } 3 \text { (formely } \\
\text { 2B), regulatory subunit B, } \\
19 \text { kda alpha isoform } \\
\text { (calcineurin B type } 1 \text { ) }\end{array}$ \\
\hline $\begin{array}{l}\text { Glyoxylate and } \\
\text { dicarboxylate } \\
\text { metabolism }\end{array}$ & dre00630 & $\mathrm{H}$ & & & \\
\hline GnRH signaling pathway & ptr04912 & A & $\mathrm{J}$ & Rpl7 & Ribosomal protein L7 \\
\hline Huntington's disease & ptr05040 & A & $\mathrm{K}$ & zgc:77235 & zgc:77235 \\
\hline Insulin signaling pathway & ptr04910 & A & & & \\
\hline Long-term potentiation & ptr04720 & A & & & \\
\hline MAPK signaling pathway & hsa04010 & $\mathrm{I}$ & & & \\
\hline Melanogenesis & ptr04916 & A & & & \\
\hline $\begin{array}{l}\text { Natural killer cell mediated } \\
\text { cytotoxicity }\end{array}$ & hsa04650 & I & & & \\
\hline Nitrogen metabolism & dre00910 & $\mathrm{D}$ & & & \\
\hline Olfactory transduction & ptr04740 & A & & & \\
\hline Oxidative phosphorylation & hsa00190 & $\mathrm{B}, \mathrm{C}$ & & & \\
\hline Peptidoglycan biosynthesis & dre00550 & $\mathrm{D}$ & & & \\
\hline $\begin{array}{l}\text { Phosphatidylinositol } \\
\text { signaling system }\end{array}$ & ptr04070 & A & & & \\
\hline Pyruvate metabolism & dre00620 & $\mathrm{H}$ & & & \\
\hline $\begin{array}{l}\text { Reductive carboxylate } \\
\text { cycle }\left(\mathrm{CO}_{2} \text { fixation }\right)\end{array}$ & hsa00720 & $\mathrm{F}, \mathrm{H}$ & & & \\
\hline Ribosome & dre03010 & $\mathrm{J}, \mathrm{K}$ & & & \\
\hline $\mathrm{T}$ cell receptor & hsa04660 & I & & & \\
\hline VEGF signaling pathway & hsa04370 & I & & & \\
\hline Wnt signaling pathway & hsa04310 & I & & & \\
\hline
\end{tabular}

minnow brain cDNA microarrays performed well with $43.3 \%$ of overall targets contributing to the statistical analysis (Table 1) and low variation in expression among replicates (Table 2, and Table S3). Given the clone-based cDNA format of the microarray, there was some target redundancy that resulted in multiple microarray targets representing a given transcript (Table 2, and Table S3). Although the transcript identities suggest redundancy, the cDNA clones are unique representing random lengths of the protein coding sequence as well as alternative splice variants which influence hybridization potential on the microarray and therefore represent a potential confounding factor for interpretation of the results. For example, investigation of RDX effects on beta globin 2 gene (Ba2 (a), accession \# AAH76356.1) indicated that 4 of 9, 1 of 9 , and 8 of 9 microarray targets had decreased expression at the $0.625,2.5$ and $10 \mathrm{mg} / \mathrm{L}$ treatments, respectively (Table 2 ). We recommend using a weight of evidence approach when interpreting these results where the $2.5,0.625$ and $10 \mathrm{mg} / \mathrm{L}$ exposures have low, medium and high support for differential expression. The results of RT-qPCR analysis corroborated the utility of this approach where significant decreased expression at the 0.625 and the $10 \mathrm{mg} / \mathrm{L}$ concentrations, but not the $2.5 \mathrm{mg} / \mathrm{L}$ concentration were observed (Table 4).

Although RDX did not cause a significant impact on survivorship except at the highest exposure concentration $(10 \mathrm{mg} / \mathrm{L})$ in the 10 day exposure (Fig. 2), significant alterations in transcript expression were observed at all RDX concentrations examined (Tables 2 and 4). The differential expression of transcripts in RDX exposures provided mechanistic insights into both the lethal and sublethal impacts of RDX. A broad interpretation of the expression results was utilized to describe all plausible mechanisms of action by which RDX may have elicited toxicological impacts in fathead minnow. Specifically, effects of RDX included alterations in the expression of transcripts coding for genes involved in 7 major biological/biochemical processes: oxygen transport, oxidative stress, neurological function, calcium binding/signaling, energy metabolism, cell growth/division and ubiquitination.

\subsection{Oxygen transport}

Energetic nitrogenous compounds have been shown to react with the iron moiety of the hemoglobin molecule causing insufficient oxygen transport (Chandra et al., 1995; Levine et al., 1984) in biological systems. Both microarray and RT-qPCR results indicated that hemoglobin alpha subunit I (Hbaa1) and beta globin 2 (Ba2) transcript expression were impaired in RDX-exposed fathead minnow (Table 4) which would therefore contribute to a deficit in overall globin synthesis. The observed differential transcript expression of the globin components in brain tissue in response to RDX exposure was a surprising result given that the globin products are typically expressed in organs responsible for hematopoiesis. It is unclear why these transcripts are expressed in brain tissues, however we envision three possible explanations for this result: (1) There may have been small amounts of blood as a contaminant from dissections that was carried over with each brain tissue sam- 
Table 4

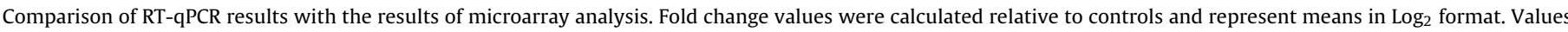

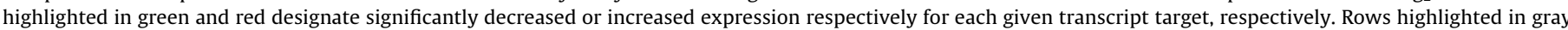

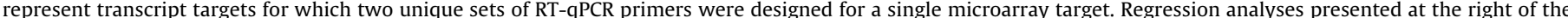

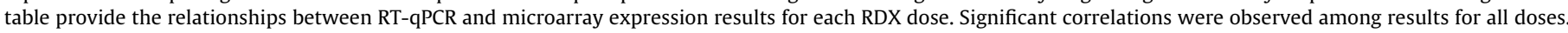

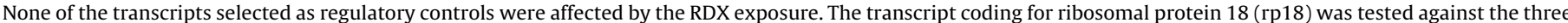
regulatory controls listed below and found not to be affected by RDX exposure. Rp18 was selected as the regulatory control for experiment-wide relative quantification.

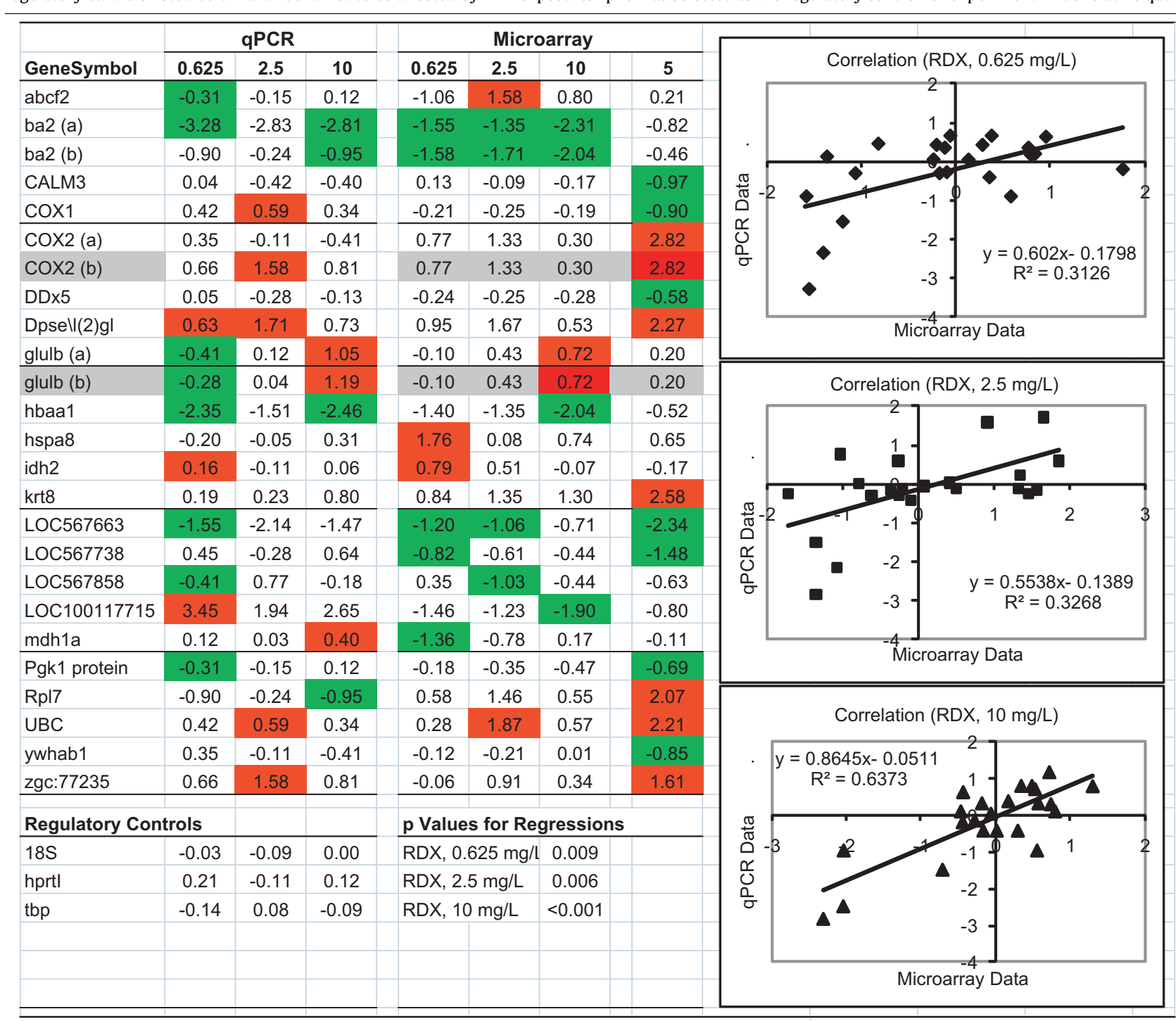

ple leading to observed globin expression and therefore providing an indication of processes occurring in hematopoietic tissues. Alternatively, (2) the targets identified as heme groups may be paralogs coding for neuroglobins which have been observed to support oxygen transport and aerobic respiration in the CNS (Burmester and Hanklen, 2004), or (3) these globin molecules truly represent heme groups that are differentially expressed in brain tissue for presently unknown reasons. Ultimately, the globin molecules are recognized to support oxygen transport in a variety of organs including blood, muscle and the CNS and decreased transcript expression in response to RDX exposure indicates potential decreased capacity for systemic oxygen transport.

\subsection{Oxidative stress, ischemia and hypoxia}

A suite of transcripts coding for genes indicative of oxidative stress, ischemia and hypoxia were observed to be differentially expressed in RDX exposures. For example, increased transcript expression of Eef $1 \alpha$ is indicative of oxidative stress and the gene product has been demonstrated to take part in apoptosis, especially in response to oxidative stress (Chen et al., 2000; Duttaroy et al., 1998). Mitochondrial isocitrate dehydrogenase 2 (Idh2) is induced by reactive oxygen species (ROS) and has been shown to be affective at combating oxidative stress through its production of NADPH (Jo et al., 2001). Expression of Idh2 transcript was increased in RDX exposure suggesting oxidative stress in brain tissue. Levels of Idh2 are usually very low in brain compared to other tissues making the tissue more susceptible to oxidative stress (Yang et al., 1996; Stein et al., 1967). Another indication that RDX may be causing oxidative stress was the increased transcript expression of heat shock protein 70 (hspa8, Tables 2 and 4), a constituent of the molecular chaperone system (HSP70) (Gophna and Ron, 2003). Within this system, HSP70 protects against proteotoxic stress and prohibits accumulation of damaged proteins. Heat shock proteins have been reported to be neuroprotective, especially following ischemia (Yenari et al., 1999). Hypoxia has also been reported to correlate with an increase 
in HSP70 (Ma and Haddad, 1997). Given the impacts on transcripts coding for genes related to globin production and oxygen transport described above, protective mechanisms to combat ischemia and hypoxia are expected. In addition to HSP70 transcript expression, the decreased transcript expression of neurogranin, which was observed in RDX-exposed fathead minnow brain tissue, has been found to be an indicator of ischemic conditions (Shughrue and Merchenthaler, 2003). Overall, the impacts of RDX appear conducive to oxidative stress, ischemia and hypoxia in fathead minnow brain tissue, as evidenced by the induction of molecular mechanisms to mitigate the ill effects of these symptoms.

\subsection{Neurological function}

Seizures have been observed in rats (Meyer et al., 2005), miniature swine (Schneider et al., 1977), mice (Dilley et al., 1978), Northern bobwhite quail (Johnson et al., 2007, Quinn et al., 2009 and Gust et al., 2009) and humans (Stone et al., 1969; Woody et al., 1986) within hours after exposure to RDX. Gust et al. (2009) hypothesized that the mode of action underlying RDX-induced seizures in Northern bobwhite is the inhibition of neuronal membrane depolarization back to the baseline voltage after an action potential thereby resulting in hyper-excitation. In that study, a variety of molecular mechanisms contributed to the mode of action including impacts on glutamate metabolism, $\mathrm{Na}^{+}$and $\mathrm{K}^{+}$ion transporters, $\mathrm{Cl}^{-}$ion channels, $\mathrm{Ca} 2+$ signaling and neurotransmitter release factors. Similar to Northern bobwhite, transcripts related to glutamate metabolism were impacted by RDX exposure in fathead minnow including increased transcript expression of glutamine synthetase (glulb, Table 4), the enzyme responsible for the conversion of the excitatory neurotransmitter glutamate (Meldrum, 2000) to non-active glutamine (Winkler et al., 1999). A shift in equilibrium from glutamine to glutamate is consistent with the decrease in kainate receptor alpha subunit (Si:ch211-251b21.1) expression as it is solely dependent on glutamate for cation channel opening (Meldrum, 2000). The decrease in kainate receptor alpha subunit transcript expression is consistent with mitigation of neuronal hyper-excitation in response to free glutamate. As will be discussed in the following section, several transcripts related to $\mathrm{Ca} 2+$ binding and signaling were also impacted in RDX exposures and have implications related to neural physiology and neuronal excitation. Although RDX exposures elicited a suite of effects on transcript expression related to neuronal excitation, no overt neuromuscular anomalies were observed in fathead minnow. It should be noted, however, that our exposure bioassay did not quantify any subtle changes in animal behavior that may have resulted from impacts on neurophysiology.

\subsection{Calcium binding and signaling}

RDX exposure reduced expression of at least three transcripts associated with calcium binding, transport, and signaling (Tables 2 and 4) including genes coding for calmodulin 1 (CALM3), calcineurin B (PPP3R1), and neurogranin (LOC567663). As we described above, one critical component of the inhibited neuronal repolarization which lead to seizures in Northern bobwhite was the inhibited sequestration of excitatory free $\mathrm{Ca} 2+$ resulting from reduced expression of calmodulin (Gust et al., 2009). Similarly, microarray results suggested reduced expression of calmodulin in RDX exposures in fathead minnow (Table 2). In conjunction with the observed impacts on calmodulin expression, RDX also impaired transcript expression of calcineurin $B$, the regulatory subunit of calciuneurin $\mathrm{Ca} 2+$ binding site which is also involved in calmodulin and $\mathrm{Ca} 2+$ dependent signal transduction pathways (Rusnak and Mertz, 2000). Neurogranin, expressed solely in brain tissue with the highest expression in dendritic spines, binds to calmodulin when $\mathrm{Ca} 2+$ levels are low or absent and therefore affects $\mathrm{Ca} 2+$ and Ca-calmodulin signaling pathways by serving as a $\mathrm{Ca} 2+$ capacitor (Gerendasy and Sutcliffe, 1997; Huang et al., 2004; Chakravarthy et al., 1999). By acting as a capacitor, neurogranin not only plays a role in signaling but learning, memory, and neural plasticity as well (Pak et al., 2000; Gerendasy and Sutcliffe, 1997; Huang et al., 2004). In an event of neuronal over-excitation of glutamate receptors, as discussed above, reduced neurogranin transcription may be the result of excess production of NO by nNOS (Gui et al., 2007; Wu et al., 2003). Oxidants produced due to oxidative stress, can decrease the binding affinity between neurogranin and calmodulin (Huang et al., 2004) impacting signal transduction. The RDX-related impacts on calcium binding and signaling indicate the potential for impacts on neurophysiology and signal transduction in fathead minnow brain tissue.

\subsection{Energy metabolism}

Several transcripts coding for proteins involved in processes driving energy production including: those involved in glycolysis [phosphoglycerate kinase I (Pgk1) and glyceraldehyde 3-phosphate dehydrogenase $\left(\mathrm{Gpd} 3\right.$, aka $\left.\mathrm{GAPDH}^{+}\right)$], the citric acid cycle [malate dehydrogenase (mdh1a)] and the electron transport chain [Isocitrate dehydrogenase (idh2, aka 2NADP+), cytochrome B (CYTB), and cytochrome coxidase subunit I and II (COXI and COXII)] were differentially expressed in RDX-exposed animals (Tables 2-4). Increased transcript expression of Gpd3 and decreased transcript expression of Pgk1 suggest competing dynamics in substrate metabolism in the glycolytic pathway which may ultimately be a compensatory response to maintain glycolysis at a functional rate. The differential transcript expression of mdh1a is an indicator that malate availability as a substrate for the citric acid cycle may be affected by RDX exposure. As well, increased transcript expression of idh2 suggests increased capacity for NADH formation during citric acid cycle metabolism and early stages of electron transport and therefore, increased substrate available for ATP production in downstream electron transport reactions. Both cytochrome b and cytochrome c oxidase proteins facilitate electron transfer in the electron transport chain to produce ATP. Our transcript expression analysis indicated that these cytochrome-coding transcripts predominantly had increased expression suggesting increased potential for ATP production. Overall, the observed changes in expression of transcripts coding for key genes involved in energy metabolism suggests an increased production of cellular energy in response to RDX exposure likely facilitated to maintain normal bioenergetics of CNS function.

\subsection{Cell cycle and cell proliferation}

RDX exposure caused differential expression of several transcripts coding for genes involved in cell cycle and cell proliferation including: increased transcript expression of ribosomal protein L7 (Rpl7), Lethal (2) giant larvae gene (Dpse/L(2)gl), glyceraldehyde 3-phosphate dehydrogenase ( $\mathrm{Gpd} 3$ ), eukaryotic elongation factor 1 alpha isoform 3 (Eef1a3) genes and reduced expression of DEAD (named due to the conserved motif Asp-Glu-Ala-Asp) box protein RNA helicase (DdX5) and vitronectin (vtnb) genes. Besides participating in translation, Rpl7 has been shown to arrest cells in the G1 stage of the cell cycle and induce apoptosis (Neumann and Krawinkel, 1997). The Dpse/L(2)gl gene which acts like a tumor suppressor gene and controls cell proliferation and differentiation (Jacob et al., 1987) also functions in cell polarity in relation to asymmetric cell division of neuroblasts (Albertson and Doe, 2003). Gpd3 has been observed to have increased expression during apoptosis and may serve a role in its initiation (Tarze et al., 2007). Eef1a3 has been shown to play a role in cell proliferation as well as catalyzing 
the first step of the elongation cycle and being involved in several cellular processes including: embryogenesis, senescence, oncogenic transformation, and cytoskeleton organization (Lamberti et al., 2004; Gangwani et al., 1998). Ddx5 is a transcriptional coregulator of a number of genes including tumor suppressor gene p53 which regulates cell proliferation (Fuller-Pace and Ali, 2008). Finally, vtnb functions in cell spreading, cell adhesion, and prevents against membrane-damage due to the complement cascade (Tomasini and Mosher, 1991). In total, the differential expression of this suite of transcripts coding for genes involved in cell cycle and cell proliferation in RDX exposures suggests that cells may have launched mechanisms to inhibit cell cycling, reduce cell proliferation and possibly initiate cell death via apoptosis in fathead minnow brain tissue. Further investigation of RDX impacts at the cellular level is recommended to determine the implications of these observed transcript expression changes.

\subsection{Ubiquitination}

Expression of a handful of transcripts coding for genes related to ubiquitination processes were observed to be affected in RDX exposures. Increased transcript expression of genes coding for ubiquitin-conjugating enzyme (LOC724793) and eukaryotic elongation factor 1 alpha (Eef1a3) were observed whereas Fbox (LOC567738) had decreased expression in RDX exposures. Ubiquitin-conjugating enzyme performs the second step of ubiquitination, the transfer of ubiquitin. Besides being involved in protein synthesis, Eef1a is believed to be involved in protein degradation processes. Two hypotheses for its role in protein degradation including that it acts as a ubiquitin C-terminal hydrolase making it easier for degradation by the $26 \mathrm{~S}$ protease or by operating as a chaperon causing correct protein folding of the protein/ubiquitin complex for proper degradation (Gonen et al., 1996a,b). The role of the F-box protein (Fbox 21) is to recruit proteins designated for degradation to the ligase complex so they will be ubiquitinated (Dardente et al., 2008). Although we cannot make a direct tie to an observed phenotype, our results suggest that RDX exposure may affect protein cycling dynamics in brain cells of fathead minnow.

\section{Conclusions}

This study represents a comprehensive investigation of the effects that RDX exposure elicited on transcript expression in fathead minnow brain tissue. To execute this research, we first sequenced and annotated a de novo cDNA library representing transcripts expressed in fathead minnow brain tissue (Fig. 3). From this effort a novel 4128 target microarray was developed which provided robust performance in transcript expression assays (Table 1). Regarding the overt toxicity of RDX, the only effects observed in the 10d RDX exposure was a significant increase in mortality (Fig. 2A) and non-significant but potentially biologically significant decrease in body weight (Fig. 2B) at the highest exposure concentration $(10 \mathrm{mg} / \mathrm{L})$. However, RDX exposure caused alterations in transcript expression in brain tissue at the lowest RDX concentration $(0.625 \mathrm{mg} / \mathrm{L})$ and throughout the concentration range (Table 2, and Table S3). Our microarray analysis detected 154 differentially expressed targets representing 44 unique transcript identities, many of which were validated by RT-qPCR (Table 4). Using a broad interpretation of the overall transcript expression results including effects on molecular pathways (Table 3 ), gene ontology (Fig. 4) and individual gene functions (Tables 2 and 4) provided hypothetical mechanisms of action by which RDX exposures affected metabolic processes involved in: oxygen transport, oxidative stress, neurological function, calcium binding/signaling, energy metabolism, cell cycle/cell proliferation and ubiquitination in fathead minnow brain tissues. Further, the impacts on neurological function and calcium binding of RDX-exposed fathead minnow have many parallels with expression observed in RDXexposed Northern bobwhite (Gust et al., 2009) and rat (Bannon et al., 2009) suggesting conservation of RDX effects across phylogenetically disparate species. This screening-level analysis provides a broad complement of probable mechanistic impacts elicited by RDX exposure in fathead minnow which should be considered for further study and validation. All inferences to function are based on observations of transcript expression. Transcript expression may provide an accurate indication of impacts for a variety of downstream gene products. However, post-transcriptional regulation of gene product level should certainly be considered. For future investigations, we recommend the use of proteomic and enzyme-specific assays to test the hypothesized mechanistic impacts of RDX exposure in fathead minnow.

\section{Acknowledgements}

We thank the anonymous peer reviewers for their comments which greatly improved the final version of this paper. This work was supported by the US Army Environmental Quality Technology Research Program. Permission was granted by the Chief of Engineers to publish this information.

\section{Appendix A. Supplementary data}

Supplementary data associated with this article can be found, in the online version, at doi:10.1016/j.aquatox.2010.09.011.

\section{References}

Ankley, G.T., Villeneuve, D.L., 2006. The fathead minnow in aquatic toxicology: past, present and future. Aquat. Toxicol. 78, 91-102.

Albertson, R., Doe, C.Q., 2003. Dlg Scrib and Lgl regulate neuroblast cell size and mitotic spindle asymmetry. Nat. Cell Biol. 5, 166-170.

Bannon, D.I., Dillman, J.F., Hable, M.A., Phillips, C.S., Perkins, E.J., 2009. Global gene expression in rat brain and liver after oral exposure to the explosive hexahydro1,3,5-triazine (RDX). Chem. Res. Toxicol. 22 (4), 620-625.

Beissbarth, T., Speed, T.P., 2004. GOstat: Find statistically overrepresented Gene Ontologies within a group of genes. Bioinformatics 20 (9), 14641465.

Burmester, T., Hanklen, T., 2004. Neuroglobin: a respiratory protein of the nervous. News Physiol. Sci. 19, 110-113.

Burton, D.T., Turley, S.D., Peters, G.T., 1994. The acute and chronic toxicity of hexahydro-1,3,5-trinitro-1,3,5-triazine (RDX) to the fathead minnow (Pimephales promelas). Chemoshphere 29, 567-579.

Chen, E., Proestou, G., Bourbeau, D., Wang, E., 2000. Rapid up-regulation of peptide elongation factor EF-1 protein levels in an immediate early event during oxidative stress-induced apoptosis. Exp. Cell Res. 259, 140-148.

Chakravarthy, B., Morley, P., Whitfield, J., 1999. Ca2_-calmodulin and protein kinase Cs: a hypothetical synthesis of their conflicting convergenceson shared substrate domains. Trends Neurosci. 22, 12-16.

Chandra, A.M., Meinkoth, J., Reddy, G., Qualls Jr., C.W., 1995. Hematological effects of 1,3,5-trinitrobenzene (TNB) in rats in vivo and in vitro. J. Toxicol. Environ. Health 46, 57-72.

Churchill, G.A., 2002. Fundamentals of experimental design for cDNA microarrays Nat. Genet. 32, 490-495.

Conesa, A., Gotz, S., 2008. Blast2GO: a comprehensive suite forfunctional analysis in plant genomics. Int. J. Plant Genomics, doi:10.1155/2008/619832.

Dardente, H., Mendoza, J., Fustin, J.M., Challet, E., Hazlerigg, D.G., 2008. Implication of the F-Box protein FBXL21 in circadian pacemaker function in mammals. PLoS ONE 3 (10), e353, doi:10.1371/journal.pone.0003530.

Diatchenko, L., Lau, Y.F., Campbell, A.P., Chenchik, A., Moqadam, F., Huang, B., Lukyanov, S., Lukyanov, K., Gurskaya, N., Sverdlov, E.D., Siebert, P.D., 1996. Suppression subtractive hybridization: A method for generating differentially regulated or tissue-specific cDNA probes and libraries. Proc. Natl. Acad. Sci. USA 93, 6025-6030.

Dilley, J.V., Tyson, C.A., Newell, G.W., 1978. Mammalian Toxicological Evaluation of TNT Wastewaters, Volume II, Acute and Subacute Mammalian Toxicity of TNT and the LAP Mixture. U.S. Army Medical Research and Development Command, ADA080957, Washington, DC.

Duttaroy, A., Bourbeau, D., Wang, X.L., Wang, E., 1998. Apoptosis rate can be accelerated or decelerated by over-expression or reduction of the level of elongation factor-1. Exp. Cell Res. 238, 168-176. 
Filby, A.L., C.R. Tyler., 2007. Appropriate housekeeping genes for use in expression profiling the effects of environmental estrogens in fish. BMC Mol. Biol.

Fuller-Pace, F.V., Ali, S., 2008. The DEAD box RNA helicases p68 (Ddx5) and p72 (Ddx17): novel transcriptional co-regulators. Biochem. Soc. Trans. 36, 609-612.

Gangwani, L., Mikrut, M., Galcheva-Gargova, Z., Davis, R.J., 1998. Interaction of ZPR1 with translation elongation factor-1alpha in proliferating cells. J Cell Biol. 143, 471-1484.

Garcia-Reyero, N., Adelman, I., Liu, L., Denslow, N., 2008. Gene expression profiles of fathead minnows exposed to surface waters above and below a sewage treatment plant in Minnesota. Mar. Environ. Res. 66 (1), 134-136.

Garcia-Reyero, N., Villenueve, D.L., Kroll, K.J., Liu, L., Orlando, E.F., Watanabe, K.H., Sepulveda, M.S., Ankley, G.T., Denslow, N.D., 2009a. Expression signatures for a model androgen and antiandrogen in the fathead minnow (Pimephales promelas) ovary. Environ. Sci. Technol. 43 (7), 2614-2619.

Garcia-Reyero, N., Kroll, D.L.K.J., Liu, L., Orlando, E.F., Watanabe, K.H., Sepulveda, M.S., Villenueve, Perkins, E.J., Ankley, G.T., Denslow, N.D., 2009b. Gene expression responses in male fathead minnows exposed to binary mixtures of an estrogen and antiestrogen. BMC Genomics 10, 308.

Gerendasy, D.D., Sutcliffe, J.G., 1997. RC3/neurogranin, a postsynaptic calpacitin for setting the response threshold to calcium influxes. Mol. Neurobiol. 15, 131-163.

Gonen, H., Dickman, D., Schwartz, A.L., Ciechanover, A., 1996a. Protein synthesis elongation factor EF-1 alpha is an isopeptidase essential for ubiquitin-dependent degradation of certain proteolytic substrates. Adv. Exp. Med. Biol. 389, 209-219.

Gonen, H., Smith, C.E., Sirgel, N.R., Kahana, C., Merrick, W.C., Chakraburity, K., Schwartz, A.L., Ciechanover, A., 1996b. Protein synthesis elongation factor EF-1_ is essential for ubiquitin- dependent degradation of certain $\mathrm{N}_{-}$-acetylated proteins and may be substitute for by bacterial elongation factor EF-Tu. Proc. Natl. Acad. Sci. U.S.A. 91, 7648-7652.

Gophna, U., Ron, E.Z., 2003. Virulence and the heat shock response. Int. J. Med. Microbiol. 292, 453-461.

Gui, J., Song, Y., Han, N.R., Sheu, F., 2007. Characterization of transcriptional regulation of neurogranin by nitric oxide and the role of neurogranin in SNP-induced cell death: implication of neurogranin in an increased neuronal susceptibility to oxidative stress. Int. J. Biol. Sci. 3 (4), 212-224.

Gust, K.A., Pirooznia, M., Quinn Jr., M.J., Johnson, M.S., Escalon, B.L., Indest, K.J., Guan, X., Clarke, J., Deng, Y., Gong, P., Perkins, E.J., 2009. Neurotoxicogenomic investigations to assess mechanisms of action of the munitions constituents RDX and 2,6-DNT in northern bobwhite (Colinus virginianus). Toxicol. Sci. 110 (1), 168-180.

Houston, J.G., Lotufo, G.R., 2005. Dietary exposure of fathead minnows to the explosives TNT and RDX and to the pesticide DDT using contaminated invertebrates. Int. J. Environ. Res. Public Health 2 (2), 286-292.

Huang, K.P., Huang, F.L., Jager, T., Li, J., Reymann, K.G., Balschun, D., 2004. Neurogranin/RC3 enhances long-term potentiation and learning by promoting calcium mediated signaling. J. Neurosci. 24, 10660-10669.

Jacob, L., Opper, M., Metzroth, B., Phannavong, B., Mechler, B.M., 1987. Structure of the $1(2)$ gl gene of Drosophila and delimitation of its tumor suppressor domain. Cell 50, 215-225.

Jo, S., Son, M., Koh, H., Lee, S., Song, I., Kim, Y., Lee, Y., Jeong, K., Kim, W., Park, J., Song, B., Huhe, T., 2001. Control of mitochondrial redox balance and cellular defense against oxidative damage by mitochondrial NADP+-dependent isocitrate dehydrogenase. J. Biol. Chem. 276 (19), 16168-16176.

Johnson, M.S., Quinn Jr., M.J., Bazar, M.A., Gust, K.A., Escalon, B.L., Perkins, E.J., 2007. Subacute toxicity of oral 2,6-dinitrotoluene and 1,3,5-trinitro-1,3,5-triazine (RDX) exposure to the northern bobwhite (Colinus virginianus). Environ. Toxicol. Chem. 26, 1481-1487.

Lamberti, A., Caraglia, M., Longo, O., Marra, M., Abbruzzese, A., Arcari, P., 2004. The translation elongation factor $1 \mathrm{~A}$ in tumorigenesis, signal transduction and apoptosis: review article. Amino Acids 26, 443-448.

Larkin, P., Villeneuve, D.L., Knoebl, I., Miracle, A.L., Carter, B.J., Liu, L., Denslow, N.D., Ankley, G.T., 2007. Development and validation of a 2000-gene microarray for the fathead minnow (Pimephales Promelas). Environ. Toxicol. Chem. 26 (7), 1497-1506.

Levine, B.S., Furedi, E.M., Gordon, D.E., Lish, P.M., Barkley, J.J., 1984. Subchronic toxicity of trinitrotoluene in Fischer 344 rats. Toxicology 32 (3), 253-265.

Ma, E., Haddad, G.G., 1997. Anoxia regulates gene expression in the central nervous system of Drosophila melanogaster. Mol. Brain Res. 46, 325-328.

Meldrum, B., 2000. Glutamate as a neurotransmitter in the brain: review of physiology and pathology. J. Nutr., 1007S-1015S

Meyer, S.A., Marchand, A.J., Hight, J.L., Roberts, G.H., Escalon, L.B., Inouye, L.S., MacMillan, D.K., 2005. Up-and-down procedure (UDP) determinations of acute oral toxicity of nitroso degradation products of hexahydro-1,3,5-trinitro-1,3,5triazine (RDX). J. Appl. Toxicol. 25, 427-434.

Neumann, F., Krawinkel, U., 1997. Constitutive expression of human ribosomal protein L7 arrests the cell cycle in G1 and induces apoptosis in jurkat T-lymphoma cells. Exp. Cell Res. 230 (2), 252-261.

Pak, J.H., Huang, F.L., Li, J., Balschun, D., Reymann, K.G., Chiang, C., Westphal, H., Huang, K.P., 2000. Involvement of neurogranin in the modulation of calcium/calmodulin-dependent protein kinase II, synaptic plasticity, and spa- tial learning: a study with knockout mice. Proc. Natl. Acad. Sci. U.S.A. 97, 11232-11237.

Pennington, J.C., Jenkins, T.F., Ampleman, G., Thiboutot, S., Brannon, J.M., Hewitt, A.D., Lewis, J., Brochu, S., Diaz, E., Walsh, M.R., Walsh, M.E., Taylor, S., Lynch, J.C. Clausen, J., Ranney, T.A., Ramsey, C.A., Hayes, C.A., Grant, C.L., Collins, C.M., Bigl, S.R., Yost, S., Dontsova, K., 2006. Distribution and Fate of Energetics on DoD Test and Training Ranges: Final Report, Engineer Research and Development Center. United States Army Corps of Engineers.

Pirooznia, M., Gong, P., Guan, X., Inouye, L.S., Yang, K., Perkins, E.J., Deng, Y., 2007. Cloning, analysis and functional annotation of expressed sequence tags from the earthworm Eisenia fetida. BMC Bioinformatics 8 (Suppl. 7), S7.

Pirooznia, M., Habib, T., Perkins, E.J., Deng, Y., 2008. GOfetcher: a database with complex searching facility for gene ontology. Bioinformatics 24 (21), 25612563.

Quinn Jr., M.J., Bazar, M.A., McFarland, C.A., Perkins, E.J., Gust, K.A., Johnson, M.S., 2009. Sublethal effects of subacute exposure to RDX (1,3,5-trinitro-1,3,5triazine) in the northern nobwhite, Colinus virginianus. Environ. Toxicol. Chem. 28 (6), 1266-1270.

Rawat, A., Gust, K.A., Deng, Y., Garcia-Reyero, N., Quinn Jr., M.J., Johnson, M.S., Indest, K., Elasri, M.O., Perkins, E.J., 2010. From raw materials to validated system: the construction of genomic library and microarray to interpret systemic perturbation in Northern Bobwhite. Physiol. Genomics 42, 219-235.

Rusnak, F., Mertz, P., 2000. Calcineurin: form and function. Physiol. Rev. 80 (4), $1483-1521$.

Schneider, N.R., Bradley, S.L., Andersen, M.E., 1977. Toxicology of cyclotrimethylenetrinitramine: distrubtion and metabolism in the rat and the miniature swine. Toxicol. Appl. Pharmacol. 39, 531-541.

Shughrue, P.J., Merchenthaler, I., 2003. Estrogen prevents the loss of CA1 hippocampal neurons in gerbils after ischemic injury. Neuroscience 116, 851-861.

Stein, A.M., Stein, J.H., Kirkman, S.K., 1967. Diphosphopyridine nucleotide specific isocitric dehydrogenase of mammalian mitochondria I. On the roles of pyridine nucleotide transhydrogenase and the isocitric dehydrogenases in the respiration of mitochondria of normal and neoplastic tissues. Biochemistry 6, 13701379.

Stone, W.J., Paletta, T.L., Heiman, E.M., Bruce, J.I., Knepshield, J.H., 1969. Toxic effects following ingestion of C-4 plastic explosive. Arch. Intern. Med. 124, 726730.

Talmage, S.S., Opresko, D.M., Maxwell, C.J., Christopher, J.E., Welsh, F.M.C., Reno, P.H., Daniel, F.B., 1999. Nitroaromatic munition compounds: environmental effects and screening values. Rev. Environ. Contam. Toxicol. 161, 1-156.

Tarze, A., Deniaud, A., Le Bras, M., Maillier, E., Molle, D., Larochette, N., Zamzami, N., Jan, G., Kroemer, G., Brenner, C., 2007. GAPDH, a novel regulator of the pro-apoptotic mitochondrial membrane permeabilization. Oncogene 26 (18), 2606-2620.

Tomasini, B.R., Mosher, D.F., 1991. Saunders, Philadelphia. Vitronectin. Progr. Hemost. Thrombos. 10, 269-305.

Townsend, J.P., Hartl, D.L., 2002. Bayesian analysis of gene expression levels: statistical quantification of relative mRNA level across multiple strains or treatments. Genome Biol. 3 (12), 0071.1-0071.16.

US Environmental Protection Agency, 2002. Methods for Measuring the Acute Toxicity of Effluents and Receiving Waters to Freshwater and Marine Organisms, EPA-821-R-02-012. United States Environmental Protection Agency, Washington, DC.

US Environmental Protection Agency, 2002b. Short-term Methods for Estimating the Chronic Toxicity of Effluents and Receiving Waters to Freshwater Organisms, EPA-821-R-02-013. United States Environmental Protection Agency, Washington, DC.

Winkler, B.S., Kapousta-Bruneau, N., Arnold, M.J., Green, D.J., 1999. Effects of inhibiting glutamine synthetase and blocking glutamate uptake on $b$-wave generation in the isolated rat retina. Vis. Neurosci. 16 (2), 345-353.

Wintz, H., Yoo, L.J., Loguinov, A., Wu, Y., Steevens, J.A., Holland, R.D., Beger, R.D., Perkins, E.J., Hughes, O., Vulpe, C.D., 2006. Gene expression profiles in fathead minnow exposed to 2,4-DNT: correlation with toxicity in mammals. Toxicol. Sci. 94 (1), 71-82

Woody, R.C., Kearns, G.L., Brewster, M.A., Turley, C.P., Shapr, G.B., Lake, R.S., 1986. The neurotoxicity of yclotrimethylenetrinitramine (RDX) in a child: a clinical and pharmacokinetic evaluation. Clin. Toxicol. 24, 305-319.

Wu, J., Huang, K.P., Huang, F.L., 2003. Participation of NMDA-mediated phosphorylation and oxidation of neurogranin in the regulation of $\mathrm{Ca} 2+-$ and $\mathrm{Ca} 2+/$ calmodulin-dependent neuronal signaling in the hippocampus. J. Neurochem. 86, 1524-1533.

Yang, L., Luo, H., Vinay, P., Wu, J., 1996. Molecular cloning of the cDNA of mouse mitochondrial NADP-dependent isocitrate dehydrogenase and the expression of the gene during lymphocyte activation. J. Cell. Biochem. 60, 400-410.

Yenari, M.A., Giffard, A.G., Sapolsky, R.M., Steinberg, G.K., 1999. The neuroprotective potential of heat shock protein 70 (HSP70). Mol. Med. Today 5 (12), 525-531.

Zhang, B., Schmoyer, D., Kirov, S., Snoddy, J., 2004. GOTree Machine (GOTM): a webbased platform for interpreting sets of interesting genes using gene ontology hierarchies. BMC Bioinformat. 5, 16. 